\title{
A systematic review about telemedicine in orthopedics
}

\author{
Wolf Petersen $^{1} \cdot$ Katrin Karpinski $^{1} \cdot$ Luisa Backhaus $^{1} \cdot$ Sebastian Bierke $^{1} \cdot$ Martin Häner $^{1}$
}

Received: 23 July 2020 / Accepted: 11 November 2020 / Published online: 26 February 2021

(c) The Author(s), under exclusive licence to Springer-Verlag GmbH, DE part of Springer Nature 2021

\begin{abstract}
Purpose Until now, the use of telemedical applications in orthopedics was limited to sparsely populated countries. However, due to the SARS-CoV-2 pandemic, interest in orthopedics in these procedures has increased significantly. The aim of this systematic review was to find out to what extent there is scientific evidence for the use of telemedicine in the orthopedic field. Methods A systematic literature search was carried out in various databases on randomized controlled trials (RCTs) on telemedical applications in orthopedics.

Results Altogether, 14 articles were identified that reported about a total of eight RCTs of telemedical applications in orthopedics. Two RCTs were about a patient-to-doctor video consultation and six RCTs were about telerehabilitation after knee and hip arthroplasty $(4 \times$ knee arthroplasty, one hip and knee arthroplasty, one hip arthroplasty). For the majority of outcome parameters evaluated, there were no significant differences between the study groups. The cost effectiveness of videoconsultations depended on the workload (number of patient consultations) as well as the effectiveness of telerehabilitation on the distance of the patient's home to the health care center (30 km round-trip).

Conclusion There is sufficient evidence to recommend the use of telemedical methods in orthopedics. However, more research is necessary to further expand the possibilities of telemedical methods with regard to physical examination.
\end{abstract}

Keywords COVID-19 $\cdot$ SARS-Cov-2 $\cdot$ Pandemic $\cdot$ Orthopedic surgery $\cdot$ Video consultation $\cdot$ Telerehabilitation $\cdot$ Knee arthroplasty $\cdot$ Diagnostics

\section{Introduction}

The SARS-Cov-2 pandemic has hit orthopedics and trauma surgery hard in many countries [2, 25, 32]. The novel corona virus has led to a global pandemic that has pushed health systems in individual regions to the limits of their capacity [25].

To prevent an exponential spread of SARS-Cov-2, various protective measures were necessary, which prevent droplet infection, but also transmission through contaminated surfaces. Protective measures to contain the pandemic include the distance rules $(1.5 \mathrm{~m})$, contact restrictions and wearing

Wolf Petersen

wolf.petersen@jsd.de

Katrin Karpinski

katrin.karpinski@t-online.de

1 Sportklinik Berlin und Klinik für Orthopädie und Unfallchirurgie am, Martin Luther Krankenhaus, Berlin Grunewald, Caspar-Theyß-Strasse 27-31, 14193 Berlin, Germany masks [25]. These measures significantly impair everyday clinical practice in orthopedics and trauma surgery. Precisely because the transmission of SARS-CoV-2 takes place primarily via droplets or contaminated surfaces, the clinical interest in contactless diagnostics and rehabilitation has increased in recent weeks.

To maintain clinical practice, interest in methods of telemedicine increase [32]. So far, these procedures have been of importance in sparsely populated countries such as Norway, Canada or Australia or in military medicine [7, 28, 30, 38].

In telemedicine applications, a distinction is made between doctor/therapist-to-doctor/therapist and doctor/ therapist-to-patient consultations and between synchronous and asynchronous applications $[2,15]$. In the context of the COVID-19 crisis, there is more interest in synchronous doctor-to-patient consultations to circumvent the contact blocks than in asynchronous applications or doctor/therapistto-doctor/therapist communication.

Scientific studies have demonstrated evidence of telemedical procedures in various medical fields $[1,15,37]$. 
However, a virtual orthopedic examination may lack the essential elements of palpation and the ability to perform dynamic diagnostic tests such as the Lachman or pivot shift test for the knee or various functional shoulder tests [2]. Therefore, the research question arises whether telemedical procedures are also suitable for orthopedics as it has been shown for other medical fields.

Aim of this systematic review was to find out if there is enough scientific evidence for the use of telemedicine applications in orthopedics.

\section{Materials and methods}

\section{Search details}

Between May 4, 2020 and Jun 15, 2020, a systematic literature search was carried out in various databases (PubMed, MEDLINE, EMBASE, Scopus, Google scholar) according to PRISMA criteria to identify work in which the use of telemedicine in orthopedics was examined. The present study was registered prospectively (www.crd.york.ac.uk/PROSP ERO; no.: CRD42020190759).

The following search terms were used: telemedicine, video consultation, remote consultation or telerehabilitation and orthopedics, orthopedic surgery or trauma surgery. If a corresponding study was found, related articles were searched in PubMed and searched for relevant publications. In addition, the reference section of relevant studies was also checked.

The main search was carried out by two reviewers (LB and WP). Inclusion and exclusion criteria were used for article selection. Inclusion criteria were: (1) use of telemedicine in orthopedics, (2) randomized controlled trial (RCT), (3) use of synchronous videoconferencing systems, (4) patients with a health problem related to the musculoskeletal system, and (5) English language. Exclusion criteria were: (1) any other specialty than orthopedics, (2) doctor/therapist to doctor/therapist communication, (3) observational studies including case-series, case-reports, case-controls, crosssectional, and cohort studies (4) unpublished studies, trial designs and conference abstracts, (5) recommendation and guideline papers, previous systematic reviews, previous meta-analysis.

Multiple articles of one clinical trial were included as far as they reported different outcome parameter.

For this review, telemedicine was defined as synchronous or asynchronous consultation using information and communication technology to omit geographical and functional distance.

Its goals are for diagnostics or treatment between two or more geographically separated health providers (for example, physicians or nurses) or between health providers and patients and include second expert opinions, tele-management, referrals, and rehabilitation.

\section{Risk of bias (quality) assessment}

The quality of all included studies was evaluated according to Jadad Score and the PEDRO scales. Quality assessment was conducted by WP.

\section{Data extraction (selection and coding)}

After researching the literature according to the specified inclusion and exclusion criteria WP and SB have extracted the following data from the selected studies:

1. Study details - journal of publication, date of publication, country/countries where study took place, sample size, study design, inclusion and exclusion criteria.

2. Telemedicine details.

3. Patient details - demographic data, specialty field (e.g. arthroplasty, sports trauma, knee, shoulder, military medicine).

4. Outcome measures (Evaluation of the effectiveness of the telemedical consultation by the doctor, cost analysis, PROMs).

\section{Strategy for data synthesis}

WP and SB have constructed a narrative synthesis of the extracted data, structured around the type of telemedicine performed, clinical characteristics, and type of outcome. Tables have been developed to aid the presentation of the extracted data along with the quality assessment. A formal meta-analysis was not planned, because it was not expected that the studies are sufficiently homogenous in terms of participants, interventions and outcomes to provide a meaningful summary.

\section{Results}

\section{Search results and study design}

The search results are shown in the Fig. 1. Detailed information about the study designs is provided in Table 1.

A total of 14 articles were identified that reported about a total of 8 RCTs of telemedical applications in orthopedics [6-8, 11, 14, 20-22, 27, 30, 33, 34, 36]. Two RCTs were about patient-to-doctor video consultation [7, 8, 14, 22, 36] and six RCTs were about telerehabilitation after knee and hip arthroplasty $(4 \times$ knee arthroplasty, one hip arthroplasty and one hip and knee arthroplasty) $[1,11,20,21,27,30$, 33, 34]. 


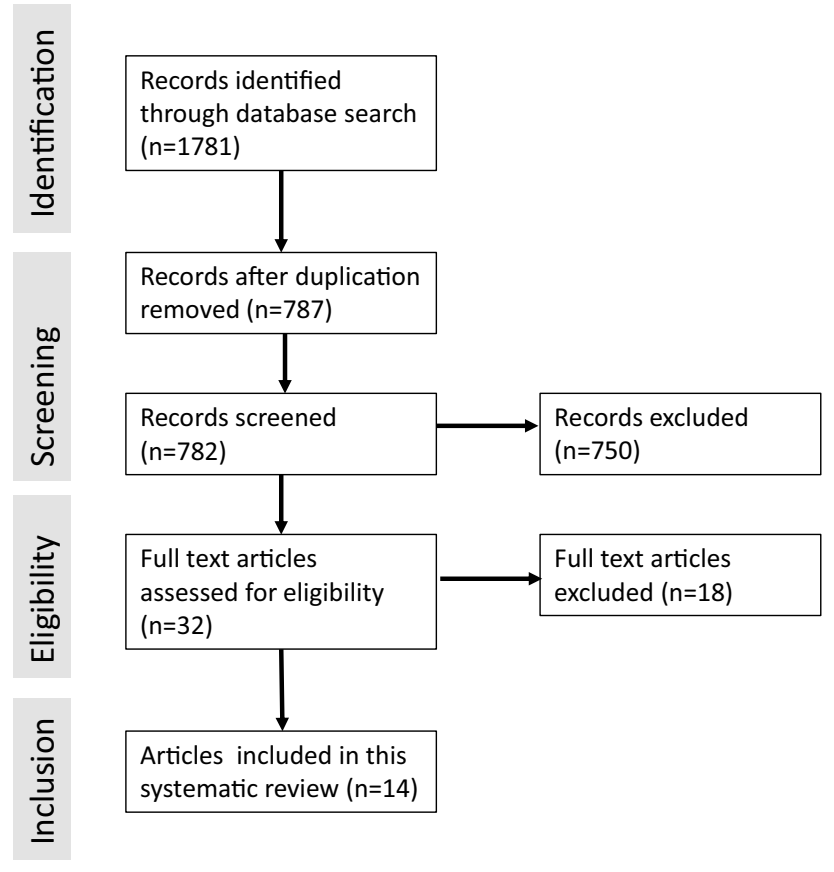

Fig. 1 Flowchart

Three articles about video consultation were part of a controlled study from Norway [6-8] and three other articles about video consultation were part of a controlled study from Finland [14, 22, 36]. Among the articles on telerehabilitation, three publications also belonged to one study. In each of these articles, different outcome parameters were reported [20, 21, 34].

Table 2 shows the results of the study quality analysis incorporating the Jadad score and the PEDRO scale. In the Jadad Score, all studies achieved a value of 3; in the PEDRO scale, the values of the analyzed studies were between 7 and 8 (Table 2).

\section{Video consultation (patient to doctor)}

Table 3 shows a summary of the study results. Two clinical trials were about a synchronous patient-to-doctor video consultation. One of these trials is from Finland and one from Norway [6-8, 14, 22, 36]. Both trials compared video consultations with standard consultation hours for orthopedic patients [6-8].

In both studies, the patients of the teleconsultation group and of the control group were equally satisfied with the specialist service and there were no differences in the therapeutical decisions (e.g. surgical indications) between the two groups $[6-8,14,22,36]$.

In the Norwegian clinical trial, there was no difference in the duration of the consultations (20.9 min standard consultation group vs. $20.5 \mathrm{~min}$ telemedicine group), complications (21\% in standard group and $17 \%$ telemedicine group) [8] and in patient-reported outcome measures (PROMs) [7].

Table 1 Study details about randomized controlled trials (rct) about the use of telemedicine in orthopaedics

\begin{tabular}{|c|c|c|c|c|c|c|c|}
\hline Study & Authors & Year & Study design & $(n)$ & Type of communiction & Country & Use \\
\hline \multirow[t]{3}{*}{1} & Haukipuro et al. [14] & 2000 & Rct & 145 & Physician-patient & Finland & Orthopedic consultation \\
\hline & Ohinmaa et al. [22] & 2002 & Ret & 145 & Physician-patient & Finland & Orthopedic consultation \\
\hline & Vuolio et al. [36] & 2003 & Rct & 145 & Physician-patient & Finland & Orthopedic consultation \\
\hline \multirow[t]{3}{*}{2} & Buvik et al. [6] & 2019 & Rct & 400 & Physician-patient & Norway & Orthopedic consultation \\
\hline & Buvik et al. [7] & 2019 & Rct & 400 & Physician-patient & Norway & Orthopedic consultation \\
\hline & Buvik et al. [8] & 2016 & Rct & 400 & Physician-patient & Norway & Orthopedic consultation \\
\hline \multirow[t]{3}{*}{3} & Moffet et al. [21] & 2015 & Rct, non-inferiority design & 205 & Physical therapist-patient, & Canada & $\begin{array}{l}\text { Telerehabilitaion in knee } \\
\text { arthroplasty }\end{array}$ \\
\hline & Moffet et al. [20] & 2017 & Rct & 205 & Physical therapist-patient & Canada & $\begin{array}{l}\text { Telerehabilitation in knee } \\
\text { arthroplasty }\end{array}$ \\
\hline & Tousignant et al. [34] & 2015 & Rct & 197 & Physical therapist-patient & Canada & $\begin{array}{l}\text { Telerehabilitation for knee } \\
\text { arthroplasty }\end{array}$ \\
\hline 4 & Piqueras et al. [27] & 2013 & Rct & 142 & Physical therapist-patient & Spain & $\begin{array}{l}\text { Telerehabilitation knee joint } \\
\text { arthroplasty }\end{array}$ \\
\hline 5 & Russel et al. [30] & 2011 & Rct, non inferiority design & 65 & Physical therapist-patient & Australien & $\begin{array}{l}\text { Telerehabilitation for knee } \\
\text { arthroplasty }\end{array}$ \\
\hline 6 & Tousignant et al. [33] & 2011 & Rct & 48 & Physical therapist-patient & Canada & $\begin{array}{l}\text { Telerehabilitation for knee } \\
\text { arthroplasty }\end{array}$ \\
\hline 7 & Vesterby et al. [35] & 2017 & Rct & 72 & Physical therapist-patient & Denmark & $\begin{array}{l}\text { Telerehabilitation for hip } \\
\text { arthroplasty }\end{array}$ \\
\hline 8 & Eichler et al. [11] & 2019 & Rct & 111 & Physical therapist-patient & Germany & $\begin{array}{l}\text { Telerehabilitation for knee and } \\
\text { hip arthroplasty }\end{array}$ \\
\hline
\end{tabular}


Table 2 Study details about randomized controlled trials (RCT) about the use of telemedicine in orthopedics

\begin{tabular}{llll}
\hline Study & Authors & Jadad score & $\begin{array}{l}\text { PEDRO } \\
\text { scale }\end{array}$ \\
\hline 1 & Haukipouro et al. [14] & 3 & 7 \\
& $\begin{array}{l}\text { Ohinmaa et al. [22] } \\
\text { Vuolio et al. [36] }\end{array}$ & & \\
& Buvik et al. [6] & 3 & 7 \\
2 & Buvik et al. [7] & & \\
& Buvik et al. [8] & & \\
& Moffet et al. [21] & 3 & 8 \\
3 & Moffet et al. [20] & & \\
& Tousignant et al. [34] & & 8 \\
& Piqueras et al. [27] & 3 & 7 \\
4 & Russel et al. [30] & 3 & 7 \\
5 & Tousignant et al. [33] & 3 & 7 \\
\hline & Vesterby et al. [35] & 3 & \\
8 & Eichler et al. [11] & 3 & \\
\hline
\end{tabular}

Both studies showed that cost effectiveness of telemedicine applications for videoconsulations depends on the workload [6, 22]. In the Norwegian study, video consultation was more cost effective after 151 patient consultations per year [6] and in the Finish study, the cost of the video consultation was lower after a workload of more than 80 patients per year [22].

\section{Telerehabilitation}

Six studies evaluated the outcome after telerehabilitation after knee or hip arthroplasty (Table 4). Four of these studies only looked at knee prosthetics, one study looked at hip arthroplasty only, and one study looked at the effect of telerehabiliation on both hip and knee arthroplasty. These studies were from Canada, Australia, Denmark, Spain and Germany $[11,20,21,27,30,33,34]$. A total of 768 patients were included in these studies.

Four studies used the Western Ontario and McMaster Universities osteoarthritis index (WOMAC) as patientreported outcome measure [11, 21, 27, 30]. The WOMAC improved in all studies without a group difference at final follow-up [11, 21, 27, 30]. In one study, better outcomes for the Patient-Specific Functional Scale and the stiffness subscale of the WOMAC were found in the telerehabilitation group [30]. In two studies, there was no significant difference in patient satisfaction between telerehabilitation and face-to-face visit [20, 30]. Four studies assessed functional parameters such as range of motion, body strength, balance, walking, or functional autonomy for patients after total knee arthroplasty [11, 21, 27, 30]. These parameters also improved from preoperative to postoperative without a group difference at final follow-up [11, 21, 27, 30].

Two studies found that patient-reported outcome measures (PROMS) and functional parameter (time up and go test) improved after conventional and telerehabilitation without a group difference $[11,35]$.

Table 3 Results of randomized controlled trials about the use of telemedicine in orthopedic consultations

\begin{tabular}{|c|c|c|}
\hline Study & Authors & Results \\
\hline \multirow[t]{3}{*}{1} & Haukipuro et al. [14] & $\begin{array}{l}\text { Videoconferencing was found to be feasible and the equipment functioned well technically. There were somewhat } \\
\text { more problems in examining the telemedicine patients than the clinic patients. The two patient groups were } \\
\text { equally satisfied with the specialist service. The telemedicine patients were more willing to have their next visit } \\
\text { by videoconferencing than the conventional patients }\end{array}$ \\
\hline & Ohinmaa et al. [22] & $\begin{array}{l}\text { At a workload of } 100 \text { patients, the total cost, including travel and indirect costs, was } 87.8 \text { per patient in the } \\
\text { telemedicine group and } 114.0 \text { per patient in the conventional group (i.e., a total cost saving from the use of tel- } \\
\text { econsultation of } 2620 \text { ). A cost-minimization analysis showed that telemedicine was less costly for society than } \\
\text { conventional care at a workload of more than } 80 \text { patients per year. If the distance to specialist care were reduced } \\
\text { from } 160 \text { to } 80 \mathrm{~km} \text {, the break-even point increased to about } 200 \text { patients per year }\end{array}$ \\
\hline & Vuolio et al. [36] & $\begin{array}{l}\text { Over half the patients had some form of regenerative arthritis: } 15 \% \text { had hip arthritis, } 33 \% \text { knee arthritis and } 4 \% \\
\text { other arthritis. There were no differences in the implementation of the management plan between the two groups }\end{array}$ \\
\hline \multirow[t]{3}{*}{2} & Buvik et al. [6] & $\begin{array}{l}\text { Cost effectiveness: video-based consultations through a distant, specialized clinic are cheaper than regular outpa- } \\
\text { tient presentations, as long as the number of teleconsultations exceeds } 151 \text { per year }\end{array}$ \\
\hline & Buvik et al. [7] & $\begin{array}{l}\text { Patient satisfaction: } 99 \% \text { of the video-supported and } 99 \% \text { of the regular outpatient group found the consultation to } \\
\text { be very satisfactory. } 86 \% \text { of the video-based group favored a video-based consultation for the next performance }\end{array}$ \\
\hline & Buvik et al. [8] & $\begin{array}{l}\text { Specialist evaluation and side effects: the primary outcome, the sum score of the specialist evaluation, was signifi- } \\
\text { cantly lower (i.e., 'better') at UNN compared to RMC }(1.72 \text { vs. } 1.82, p=0.0030) \text {. The } 90 \% \text { confidence interval } \\
\text { (CI) for the difference in score }(0.05,0.17) \text { was within the non-inferiority margin. The orthopaedic surgeons } \\
\text { involved evaluated } 98 \% \text { of the video-assisted consultations as 'good' or 'very good'. In the ancillary analyses, } \\
\text { there was no significant difference between the two groups. No serious events related to the mode of consulta- } \\
\text { tion }\end{array}$ \\
\hline
\end{tabular}


Table 4 Results of randomized controlled trials about the use of telemedicine in orthopedic rehabilitation

\begin{tabular}{|c|c|c|}
\hline Study no. & Authors & Results \\
\hline \multirow[t]{2}{*}{3} & Moffet et al. [21] & $\begin{array}{l}\text { The demographic and clinical characteristics of the two groups of patients were similar at baseline. At the last } \\
\text { follow-up evaluation, the mean differences between the groups with regard to the WOMAC gains, adjusted } \\
\text { for baseline values, were near zero (for } 182 \text { patients in the per-protocol analysis): }-1.6 \% \text { [95\% confidence } \\
\text { interval (CI): }-5.6 \%, 2.3 \% \text { ] for the total score, }-1.6 \%(95 \% \mathrm{CI}:-5.9 \%, 2.8 \% \text { ) for pain, }-0.7 \% \text { ( } 95 \% \mathrm{CI} \text { : } \\
-6.8 \%, 5.4 \% \text { ) for stiffness, and }-1.8 \%(95 \% \mathrm{CI}:-5.9 \%, 2.3 \% \text { ) for function. The confidence intervals were } \\
\text { all within the predetermined zone of non-inferiority. The secondary outcomes had similar results, as did the } \\
\text { intention-to-treat analysis, which was conducted afterward for } 198 \text { patients }\end{array}$ \\
\hline & Moffet et al. [20] & $\begin{array}{l}\text { Characteristics of all participants were similar at baseline. Satisfaction level of both groups did not differ and } \\
\text { was very high (over } 85 \% \text { ). It was neither correlated to personal characteristics nor to improvements of func- } \\
\text { tional level from preoperative to E4. Satisfaction was rather found associated to walking and stair-climbing } \\
\text { performances }\end{array}$ \\
\hline
\end{tabular}

Tousignant et al. [34] The mean cost of a single session was Can \$93.08 for the VISIT group (SD \$35.70) and \$80.99 for the TELE group (SD \$26.60). When comparing both groups, real total cost analysis showed a cost differential in favor of the TELE group (TELE minus VISIT: $-\$ 263,95 \%$ CI - \$382 to - \$143). However, when the patient's home was located less than $30 \mathrm{~km}$ round-trip from the health care center, the difference in costs between TELE and VISIT treatments was not significant $(p=0.25,0.26$, and 0.11 for the $<10,10-19$, and $20-29 \mathrm{~km}$ strata, respectively). The cost of TELE treatments was lower than VISIT treatments when the distance was $30 \mathrm{~km}$ or more $(30-49 \mathrm{~km}: \$ 81<\$ 103, p=0.002 ; \geq 50 \mathrm{~km}: \$ 90<\$ 152, p<0.001)$

$4 \quad$ Piqueras et al. [27]

Baseline characteristics between groups were comparable. All participants improved after the 2 weeks intervention on all outcome variables $(p<0.05)$. Patients in the interactive virtual telerehabilitation group achieved improvements in the functional variables similar to those achieved in the conventional therapy group

$5 \quad$ Russel et al. [30]

Baseline characteristics between groups were similar, and all participants had significant improvement on all outcome measures with the intervention $(p<0.01$ for all). After the 6-week intervention, participants in the telerehabilitation group achieved outcomes comparable to those of the conventional rehabilitation group with regard to flexion and extension range of motion, muscle strength, limb girth, pain, timed up-and-go test, quality of life, and clinical gait and WOMAC scores. Better outcomes for the Patient-Specific Functional Scale and the stiffness subscale of the WOMAC were found in the telerehabilitation group $(p<0.05)$. The telerehabilitation intervention was well received by participants, who reported a high level of satisfaction with this novel technology

Tousignant et al. [33] Clinical outcomes improved significantly for all subjects in both groups between endpoints. Some variables showed larger improvements in the usual care group two months post-discharge from therapy than in the telerehabilitation group

$7 \quad$ Vesterby et al. [36]

Length of stay was reduced from 2.1 days (95\% CI: 2.0-2.3) to 1.1 day (CI: $0.9-1.4 ; p<0.001$ ) with the TMS intervention. Health-related quality of life increased in both groups, but there were no statistically significant differences between groups. There were also no statistically significant differences between groups regarding timed up-and-go test and Oxford hip score at 3 months follow-up. At 12 months follow-up, the rates of complications and re-admissions were similar between the groups, but the number of postoperative hospital contacts was lower in the TMS group

$8 \quad$ Eichler et al. [11]

Both the intervention group (average difference $88.3 \mathrm{~m}$; SD 57.7; $p=0.95$ ) and the control group (average difference $79.6 \mathrm{~m}$; SD 48.7; $p=0.95$ ) increased their distance in the 6 min walk test. Improvements in other functional parameters, as well as in quality of life and pain, were achieved in both groups. The higher proportion of working patients in the intervention group $(64.6 \% ; p=0.01) \mathrm{vs}$. the control group $(46.2 \%)$ is of note

One study evaluated return to work after total knee and hip replacement. In this study, more patients after telerehabilitation returned to work in comparison to the control group with conventional physiotherapy (64.6 vs. $46.2 \%$ ) [11].

One study examined the cost effectiveness of telerehabilitation for knee arthroplasty [34]. This study could show that the cost of telerehabilitation was lower than face-to-face treatments when the distance to the hospital was $30 \mathrm{~km}$ or more [34].

\section{Discussion}

This systematic review shows that there is sufficient scientific evidence for recommending telemedical applications in orthopedics for consultations and rehabilitation.

Eight controlled randomized studies with good scientific quality are available for the use of telemedicine for diagnostic consultation hours in communication between doctor and patient or for use in rehabilitation between 
physiotherapist and patient $[6-8,11,14,20-22,27,30$, $33,34,36]$. These studies have shown that there is no difference between telemedical applications and conventional procedures with regard to patient satisfaction, functional outcome parameters and PROMs. Most RCTs about the use of synchronous telemedicine in orthopedics have been published on the use of videocontrolled rehabilitation after knee arthroplasty [6-8, 11, 14, 20-22, 27, 30, 33, 34, 36]. Since these are two different entities, both applications, video consultation and telerehabilitation, should be discussed separately.

The quality of the studies examined was overall good. In the Jadad score, all studies were three (maximum 5) and on the PEDRO scale, the studies were between seven and eight. In all studies, there were point deductions in both scores for the lack of blinding of the patients. In three studies, however, the scientific examiner was blinded. The lack of blinding of the patients and therapists is due to the study object. A blinding of patients and therapists is not possible in studies comparing telerehabilitation with conventional rehabilitation. Nevertheless, studies with a value on the PEDRO scale of more than five are considered to have a low risk of bias and high methodological quality [24].

\section{Diagnostic video consultations}

In telemedicine, a distinction is made between synchronous and asynchronous procedures. In this review, we focused on synchronous video-based applications (Fig. 2). However, a randomized study about a web-based follow-up after total knee or hip replacement from Canada has shown that asynchronous methods also have clinical justification [18, 19]. Nevertheless, in this study, patients in the conventional group were more satisfied with the care provided by the

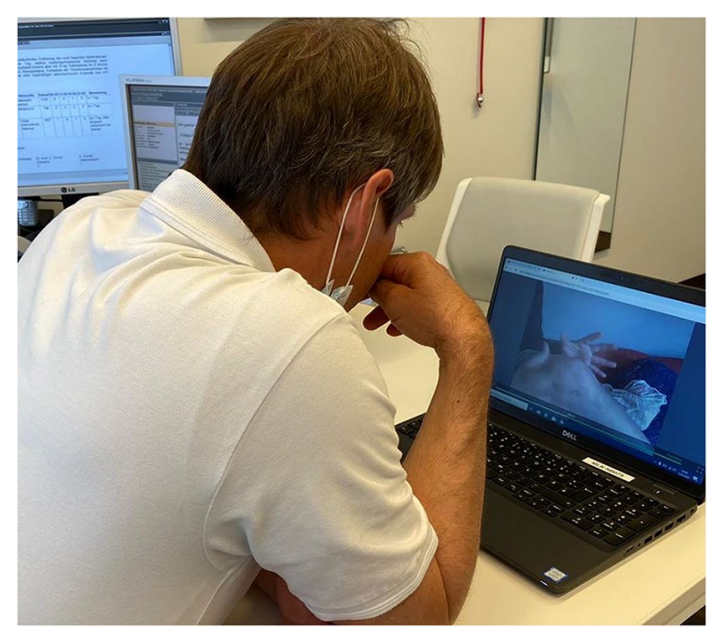

Fig. 2 Example of a video consultation with inspection of the knee joint surgeon than in the web-based group (92.8 vs. $73.9 \%$ ) [18]. One factor for less patient satisfaction with asynchronous telemedicine could be the missing contact between patient and physician [3]. Although no direct contact between patient and physician is possible with video transmission, emotions can be perceived through the screen. Therefore, contact with the patient during synchronous video consultations can probably be more empathetic. One point that remains to be investigated is if there is a difference between patients who already know their doctor in person and patients that were confronted with a doctor they never met before.

The authors of both studies on the use of synchronic telemedicine in diagnostic consultations concluded that video-supported consultations are suitable for orthopedic patients [6-8, 14, 22, 36]. However, young patients with knee problems (sports traumatological diagnoses) and shoulder patients were excluded from one study, because, according to the authors, functional examinations (knee stability, shoulder tests) play a major role in the diagnosis [6-8]. Haukipuro et al. also reported about more problems in examining the telemedicine patients than the clinic patients [14].

Despite that, the main advantage of synchronous video consultation in contrast to asynchronous telemedical applications is the possibility of a simple physical examination with inspection, detection of mobility and simple diagnostic tests [2, 32]. Inspection with assessment of skin, erythema, effusion and muscular atrophy is of central importance [2, 32]. The quality of the inspection findings naturally depends to a large extent on the quality of the image transmission [2, 32]. It, therefore, makes sense to send the patient a checklist in advance with information on how to conduct the consultation [2, 32]. It should provide information on lighting and camera position and clothing [2, 32]. Short, tight-fitting sports pants are advantageous as legwear [2, 32].

Simple diagnostic tests are also possible through video transmission [2, 32]. The quadrant method is suitable for self-palpation of the knee joint by the patient to indicate pain point [2]. The range of motion (ROM) can also be evaluated with video assistance. A web-based goniometer (Protractor; Ben Burlingham) that is compatible with most applications can be useful $[2,32]$. The reliability of measurements of the range of motion of joints on the basis of photo and video documentation was convincing in several studies $[5,9]$.

A simple meniscus test that can be carried out by the patient on his own is the Thessaly test, in which the patient stands on the affected leg and turns the body inwards and outwards [16]. Pain and mechanical abnormalities on the side of the affected meniscus are considered positive [16]. One-legged squats are another option for functional examination which are possible via video transmission [26]. However, functional stability tests for the knee and shoulder as well as provocation tests and muscle function tests are not possible with videoconsultations. The orthopaedic video 
consultation, therefore, has its limitations in the diagnosis of instabilities of the knee joint as well as shoulder diseases $[2,7,32]$. Perhaps new methods using the modern sensors can improve the possibilities for telemedicine for these areas in the future [17]. For example, a recent study showed that motion-based machine learning software has the potential to replace an examination knee within $5^{\circ}$ after goniometer measurements remotely [29]. In the future, functional diagnostics over distances can also be possible on the knee with help of sensors [17, 29].

The diagnostic possibilities described can be one reason for the positive results of a recent cohort study on the use of telemedicine in orthopedic consultations of 13 patients with shoulder instability [13]. Another cohort study from Chile showed that an orthopedic video consultation could optimize waiting times and travel times [28].

The cost effectiveness of telemedicine applications for videoconsulations depends on the workload [6, 22]. Patients in scarcely populated regions might benefit more from video consultations in terms of costs and time-effort. Nevertheless, also patients in densely populated urban regions with a fulltime job might still benefit from quickly available consultations, e.g. in their lunch break.

\section{Telerehabilitation}

The results of this systematic review are in accordance with another systematic review of the use of telemedicine to monitor postoperative rehabilitation which was published in 2017 [23]. In contrast to the present study, inclusion to this previous systematic review was not restricted to RCTs [23]. Therefore, 15 studies with a total of 1316 participants were included in this systematic review [23]. Most of these studies involved knee and hip replacement [23]. Strong and moderate evidence existed for the telerehabilitation after knee and hip arthroplasty [23]. Of all upper limb studies, only one showed moderate level of evidence [23]. The rest of the upper limb studies were of poor methodological quality with poor evidence [23]

The results of the present systematic review confirm these findings. RCT could only be found for the use of synchronous telemedicine for the rehabilitation after knee and hip replacement $[1,10,11,20,21,27,30,33,34]$. This is probably due to the fact that joint replacement is a very common orthopedic operation and that rehabilitation after joint replacement is highly standardized.

The results of the identified RCT showed that there is no difference between telerehabilitation and conventional rehabilitation after joint arthroplasty of the lower extremity with regard to PROMs and functional outcome parameters $[1,10,11,20,21,27,30,33,34]$. However, telerehabilitation was more costeffective in comparison to conventional

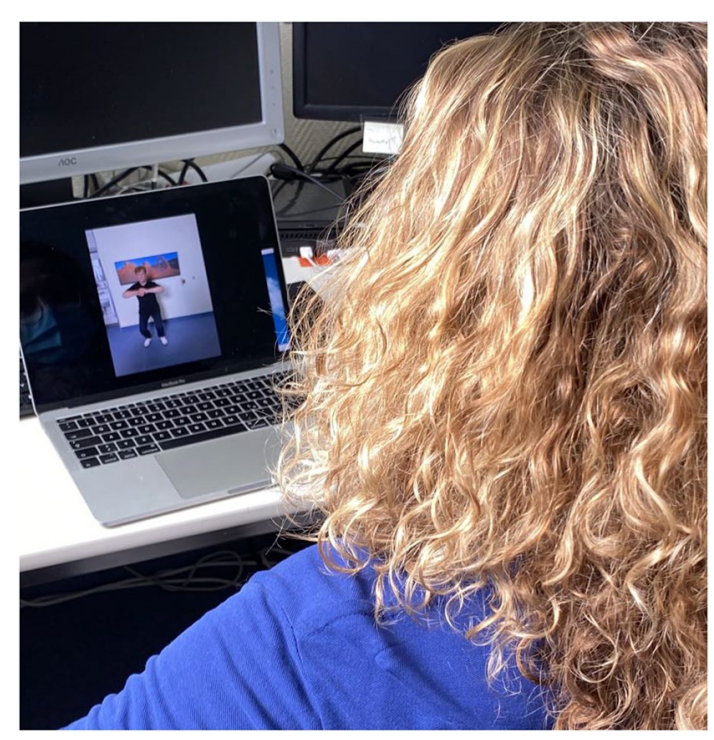

Fig. 3 Example of a telerehabilitation with correction of the exertion of the excercises of the patient by a physiotherapist

face-to-face rehabilitation as far as the distance between physical therapist and patient is more than $30 \mathrm{~km} \mathrm{[34].}$

In this systematic review, we focused on RCT about synchronous (real time) telemedicine applications (Fig. 3). The need for expensive hard- and software could be a barrier to implement video-based telerehabilitation [4]. Two recent RCT evaluated the use of an asynchronous for telerehabilitation after knee arthroplasty [4, 12]. In 1 study, 55 patients were randomized to either asynchronous telerehabilitation on a mobile device, or the control group undergoing conventional physical therapy [4]. No statistically significant differences in any clinical outcome measure or patient satisfaction between groups could be found but outpatient resource utilization was lower in the telerehabilitation group. In another RCT virtual reality-based- or traditional rehabilitation was compared [12]. In this study, also no significant differences could be found with regard to clinical outcome parameter. However, the drop out rate in the asynchronous telerehabilitation group was $13 \%$. As a possible reason for this finding, the authors indicate that the personal relationship between physiotherapist and patient is missing in asynchronous telerehabilitation (e.g., mobilization by a therapist using touch). Such factors can also serve as a stimulator for a possible placebo effect of classic physiotherapy [3]. The synchronized video-supported telerehabilitation also lacks the physical contact between patient and therapist, but there is a visual relationship with the exchange of emotions.

One way to improve the precision of telemedical examinations and findings would be to use sensors, particularly in the context of rehabilitation [17, 29]. Today, powerful motion sensors are so small that they can be attached locally to the knee and thus register movements. In addition, sensors 
are already so inexpensively available that their use in monitoring therapies and rehabilitation seems to be realistic. A recently published study showed that the movement detection of the knee joint in the sagittal plane by means of two sensors attached locally to the knee was as precise as with a marker-supported movement analysis [17, 29]. In various experimental studies, locally attached sensors have already been used to monitor rehabilitation after prosthetic knee replacement [17, 29, 31]. Another option could a camerabased motion detection [12]. Such a system was used by Eichler et al. [11]. This study was included in this systematic review, because it included synchronous elements as well as asynchronous elements. While exercising, the patients movement pattern are tracked by the camera, and an automatic real-time motion feedback in the form of green and red coloration of the single body segments for correct and incorrect movements is given [11]. After each exercise, the quality of each exercise as well as the whole training is graded, which is visible for a physiotherapist for further improvement of the training. [11]. Different options for communication between patient and therapist were provided [11]: (1) Asynchronous audio messages from patient to therapist, (2) Asynchronous response from therapist to patient, and (3) Live video conferencing that they should conduct individually [11]. Because of the synchronous tracking option and the synchronous video conferences this study was included in the present systematic review. In this RCT functional parameters, as well as the quality of life and pain, improved in both groups without a significant difference, but a higher proportion patients in the intervention group returned to work in comparison to the control group (64.6 vs. 46.2\%) [11].

A limitation of the present systematic review could be that no study blinded the patients and therapists and that no placebo control could take place. However, this is due to the study object. In our view, it is impossible to achieve blindness when examining teleconsultation and telerehabilitation. Nevertheless, all studies achieved a score above seven on the PEDRO scale, which is a sign of good study quality. This is certainly due to the focus on randomized controlled trials. However, a potential disadvantage of RCT can be the selection bias in these studies [24]. Therefore, the transfer of data into the real clinical situation should always be done with caution.

\section{Conclusion}

Despite all limitations, this systematic review shows that there is scientific evidence for telemedical applications in orthopedics for consultations and rehabilitation. The current evidence is very convincing for telerehabilitation after implantation of a knee prosthesis, since six different RCTs on this topic have already been published and because it has been shown that the results after telerehabilitation are comparable to conventional rehabilitation after knee arthroplasty. Here, the positive experiences with telerehabilitation should be transferred to other rehabilitation procedures (e.g., rehabilitation after reconstruction of the anterior cruciate ligament) in the future. Telemedical applications could be an alternative to conventional consultation and rehabilitation for sparsely populated countries, for the military, for the supervision of professional athletes (e.g., training camps), or for pandemic situations. There is potential to improve the possibilities of telemedical applications. Therefore, more research is needed in this field.

Funding There is no funding source.

\section{Compliance with ethical standards}

Conflict of interest The authors declare that they have no conflict of interest.

Ethical approval This article does not contain any studies with human participants or animals performed by any of the authors.

\section{References}

1. Agarwal S, Day DJ, Sibson L, Barry PJ, Collas D, Metcalf K, Cotter PE, Guyler P, O'Brien EW, O'Brien A, O'Kane D, OwusuAgyei P, Phillips P, Shekhar R, Warburton EA (2014) Thrombolysis delivery by a regional telestroke network-experience from the UK National Health Service. J Am Heart Assoc 3:e000408

2. Backhaus L, Bierke S, Karpinski K, Häner M, Petersen W (2020) SARS-CoV-2-Pandemie und ihre Auswirkungen auf Orthopädie und Unfallchirurgie: "Booster" für die Telemedizin Einleitung. Knie J. https://doi.org/10.1007/s43205-020-00062-z

3. Benedetti $F$ (2013) Placebo and the new physiology of the doctorpatient relationship. Physiol Rev 93(3):1207-1246

4. Bini SA, Mahajan J (2016) Clinical outcomes of remote asynchronous telerehabilitation are equivalent to traditional therapy following total knee arthroplasty: a randomized control study. J Telemed Telecare (SAGE Publications Ltd) 23:239-247

5. Blonna D, Zarkadas PC, Fitzsimmons JS, O'Driscoll SW (2012) Accuracy and inter-observer reliability of visual estimation compared to clinical goniometry of the elbow. Knee Surg Sports Traumatol Arthrosc 20:1378-1385

6. Buvik A, Bergmo TS, Bugge E, Smaabrekke A, Wilsgaard T, Olsen JA (2019) Cost-effectiveness of telemedicine in remote orthopedic consultations: randomized controlled trial. J Med Internet Res 21(2):e11330

7. Buvik A, Bugge E, Knutsen G, Småbrekke A, Wilsgaard T (2019) Patient reported outcomes with remote orthopaedic consultations by telemedicine: a randomised controlled trial. J Telemed Telecare (SAGE Publications Ltd) 25:451-459

8. Buvik A, Bugge E, Knutsen G, Småbrekke A, Wilsgaard T (2016) Quality of care for remote orthopaedic consultations using telemedicine: a randomised controlled trial. BMC Health Serv Res (BioMed Central Ltd) 16:483 
9. Dent PA, Wilke B, Terkonda S, Luther I, Shi GG (2020) Validation of teleconference-based goniometry for measuring elbow joint range of motion. Cureus 12(2):e6925

10. Eichler S, Rabe S, Salzwedel A, Müller S, Stoll J, Tilgner N, John M, Wegscheider K, Mayer F, Völler H (2017) Effectiveness of an interactive telerehabilitation system with home-based exercise training in patients after total hip or knee replacement: Study protocol for a multicenter, superiority, no-blinded randomized controlled trial. Trials (BioMed Central Ltd) 18(1):438

11. Eichler S, Salzwedel A, Rabe S, Mueller S, Mayer F, Wochatz M, Hadzic M, John M, Wegscheider K, Völler H (2019) The Effectiveness of telerehabilitation as a supplement to rehabilitation in patients after total knee or hip replacement: randomized controlled trial. JMIR Rehabil Assist Technol 6:e14236

12. Gianola S, Stucovitz E, Castellini G, Mascali M, Vanni F, Tramacere I, Banfi G, Tornese D (2020) Effects of early virtual reality-based rehabilitation in patients with total knee arthroplasty: A randomized controlled trial. Medicine 99(7):e19136

13. Gilbert AW, Jaggi A, May CR (2019) What is the acceptability of real time 1:1 videoconferencing between clinicians and patients for a follow-up consultation for multi-directional shoulder instability. Shoulder Elbow (SAGE Publications Inc) 11:53-59

14. Haukipuro K, Ohinmaa A, Winblad I, Linden T, Vuolio S (2000) The feasibility of telemedicine for orthopaedic outpatient clinics-a randomized controlled trial. J Telemed Telecare (Royal Society of Medicine Press Ltd) 6:193-198

15. Hollander JE, Carr BG (2020) Virtually perfect? Telemedicine for COVID-19. N Engl J Med 382(18):1679-1681

16. Karachalios T, Hantes M, Zibis AH, Zachos V, Karantanas AH, Malizos KN (2005) Diagnostic accuracy of a new clinical test (The Thessaly test) for early detection of meniscal tears. J Bone Joint Surg Am 87:955-962

17. Kayaalp ME, Agres AN, Reichmann J, Bashkuev M, Duda GN, Becker R (2019) Validation of a novel device for the knee monitoring of orthopaedic patients. Sensors 19(23):5193

18. Marsh J, Bryant D, MacDonald SJ, Naudie D, Remtulla A, McCalden R, Howard J, Bourne R, McAuley J (2014) Are patients satisfied with a web-based followup after total joint arthroplasty? Clin Orthop Relat Res (Springer, New York LLC) 472:1972-1981

19. Marsh J, Hoch JS, Bryant D, MacDonald SJ, Naudie D, McCalden R, Howard J, Bourne R, McAuley J (2014) Economic evaluation of web-based compared with in-person follow-up after total joint arthroplasty. J Bone Joint Surg Am 96:1910-1916

20. Moffet H, Tousignant M, Nadeau S, Mérette C, Boissy P, Corriveau H, Marquis F, Cabana F, Belzile ÉL, Ranger P, DImentberg $R$, (2017) Patient satisfaction with in-home telerehabilitation after total knee arthroplasty: results from a randomized controlled trial. Telemed J E Health 23:80-87

21. Moffet H, Tousignant M, Nadeau S, Mérette C, Boissy P, Corriveau H, Marquis F, Cabana F, Ranger P, Belzile ÉL, Dimentberg $\mathrm{R}$ (2015) In-home telerehabilitation compared with faceto-face rehabilitation after total knee arthroplasty: a noninferiority randomized controlled trial. J Bone Joint Surg Am (Lippincott Williams and Wilkins) 97:1129-1141

22. Ohinmaa A, Vuolio S, Haukipuro K, Winblad I (2002) A costminimization analysis of orthopaedic consultations using videoconferencing in comparison with conventional consulting. $\mathbf{J}$ Telemed Telecare 8:283-289

23. Pastora-Bernal JM, Martín-Valero R, Barón-López FJ, Estebanez-Pérez MJ (2017) Evidence of benefit of telerehabitation after orthopedic surgery: a systematic review. J Med Internet Res 19(4):e142

24. Petersen W, Achtnich A, Lattermann C, Kopf S (2015) The treatment of non-traumatic meniscus lesions. Dtsch Arztebl Int 112:705-713
25. Petersen W, Bierke S, Karpinski K, Häner M (2020) CoronavirusPandemie und ihre Auswirkungen auf Orthopädie und Unfallchirurgie: Operationen, Risiken und Prävention? Coronavirus pandemic and its effect on orthopedics and trauma surgery: surgery, risks and prevention? Knee J (Springer Science and Business Media LLC) 28(6):1690-1698

26. Petersen W, Ellermann A, Gösele-Koppenburg A, Best R, Rembitzki IV, Brüggemann GP, Liebau C (2014) Patellofemoral pain syndrome. Knee Surg Sports Traumatol Arthrosc 22(10):22642274. https://doi.org/10.1007/s00167-013-2759-6

27. Piqueras M, Marco E, Coll M, Escalada F, Ballester A, Cinca C, Belmonte R, Muniesa JM (2013) Effectiveness of an interactive virtual telerehabilitation system in patients after total knee arthroplasty: a randomized controlled trial. J Rehabil Med 45:392-396

28. Prada C, Izquierdo N, Traipe R, Figueroa C (2020) Results of a new telemedicine strategy in traumatology and orthopedics. Telemed E Health (Mary Ann Liebert Inc) 26:665-670

29. Ramkumar PN, Haeberle HS, Ramanathan D, Cantrell WA, Navarro SM, Mont MA, Bloomfield M, Patterson BM (2019) Remote patient monitoring using mobile health for total knee arthroplasty: validation of a wearable and machine learning-based surveillance platform. J Arthroplasty (Churchill Livingstone Inc) 34:2253-2259

30. Russell TG, Buttrum P, Wootton R, Jull GA (2011) Internet-based outpatient telerehabilitation for patients following total knee arthroplasty: a randomized controlled trial. J Bone Joint Surg Am 93:113-120

31. Small SR, Bullock GS, Khalid S, Barker K, Trivella M, Price AJ (2019) Current clinical utilisation of wearable motion sensors for the assessment of outcome following knee arthroplasty: a scoping review. BMJ Open 9(12):e033832

32. Tanaka MJ, Oh LS, Martin SD, Berkson EM (2020) Telemedicine in the era of COVID-19. J Bone Joint Surg (Ovid Technologies (Wolters Kluwer Health)) 8(5):1489-1491

33. Tousignant M, Moffet H, Boissy P, Corriveau H, Cabana F, Marquis $\mathrm{F}$ (2011) A randomized controlled trial of home telerehabilitation for post-knee arthroplasty. J Telemed Telecare 17:195-198

34. Tousignant M, Moffet H, Nadeau S, Mérette C, Boissy P, Corriveau H, Marquis F, Cabana F, Ranger P, Belzile ÉL, Dimentberg $R$ (2015) Cost analysis of in-home telerehabilitation for post-knee arthroplasty. J Med Internet Res 17(3):e83

35. Vesterby MS, Pedersen PU, Laursen M, Mikkelsen S, Larsen J, Søballe K, Jørgensen LB (2017) Telemedicine support shortens length of stay after fast-track hip replacement: a randomized controlled trial. Acta Orthop (Taylor and Francis Ltd) 88:41-47

36. Vuolio S, Winblad I, Ohinmaa A, Haukipuro K (2003) Videoconferencing for orthopaedic outpatients: one-year follow-up. J Telemed Telecare 9:8-11

37. Wallace P, Haines A, Harrison R, Barber JA, Thompson S, Roberts J, Jacklin PB, Lewis L, Wainwright P (2002) Design and performance of a multi-centre randomised controlled trial andeconomic evaluation of joint tele-consultations [ISRCTN54264250]. BMC Fam Pract (BioMed Central Ltd) 3:1-8

38. Waterman BR, Laughlin MD, Belmont PJ, Schoenfeld AJ, Pallis MP (2014) Enhanced casualty care from a global military orthopaedic teleconsultation program. Injury (Elsevier Ltd) 45:1736-1740

Publisher's Note Springer Nature remains neutral with regard to jurisdictional claims in published maps and institutional affiliations. 